\title{
Simulasi Analisis Bukti Digital Pada Layanan Cloud Computing Menggunakan Metode NIST 800-86
}

\author{
Irfan Helmi, Nur Widiyasono, Rohmat Gunawan* \\ Fakultas Teknik, Program Studi Informatika, Universitas Siliwangi, Tasikmalaya, Indonesia

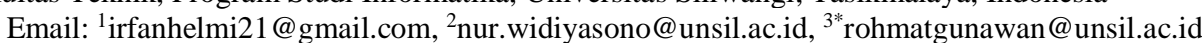

\begin{abstract}
Abstrak
Kemudahan dan fleksibilitas penyimpanan data berbasis cloud telah mendorong peningkatan jumlah penggunaan layanan cloud. Bertambahnya jumlah penggunaan layanan cloud juga berpotensi meningkatkan jumlah tindakan kriminal berbasis digital terutama berhubungan dengan penyalahgunaan fasilitas pada layanan cloud. Fitur layanan cloud yang dirancang untuk menyimpan data guna mendukung kelancaran proses bisnis, dapat disalahdigunakan oleh pelaku kriminal untuk menyimpan data hasil kejahatan. Diperolehnya bukti digital yang akurat, merupakan salah satu cara menangkap para pelaku kejahatan digital, yang selanjutnya dapat dipergunakan sebagai bukti pendukung di persidangan. Penelitian ini bertujuan untuk melakukan simulasi analisis terhadap bukti digital dari suatu layanan cloud. Proses analisis menggunakan metode NIST 800-86 dilakukan pada bukti digital dari 5 skenario yang dipersiapkan sebelumnya berkaitan dengan penggunaan fitur layanan cloud yang berpotensi disalahgunakan. Teknik akuisisi data menggunakan metode live acquisition dan physical imaging untuk mendapatkan bukti digital. Hasil percobaan pada penelitian menunjukan bahwa, setelah dilakukan skenario 1 dan skenario 3, berhasil didapatkan informasi nama file dan direktori path yang diunduh oleh client 1 dan client 2 dilengkapi dengan informasi ip address, mac address, username, password dan timestamp. Setelah dilakukan skenario 2, berhasil didapatkan bukti digital berupa informasi nama dan lokasi folder di server cloud. Setelah dilakukan skenario 4, berhasil didapatkan informasi nama file dan shared folder dilengkapi dengan informasi client yang mendapatkan hak untuk mengakses file dan folder tersebut. Setelah dilakukan skenario 5, berhasil didapatkan informasi nama file dan direktori path file yang dihapus.
\end{abstract}

Kata Kunci: Akuisisi Data, Bukti Digital, Cloud Computing, NIST800-86.

\begin{abstract}
Ease and support for cloud-based data storage It has supported an increase in the number of cloud services. The increasing number of uses for cloud services also increases the number of digital-based criminal actions related to the addition of facilities to cloud services. The cloud service feature designed to store data to support the smooth running of business processes can be misused by criminal assistance to store crime data. Accurate digital evidence is one way to prove a digital crime, which can then be used as supporting evidence in the trial. This study discusses the analysis of digital evidence from a cloud service. The analysis process using the NIST 800-86 method is carried out on digital evidence from 5 previously prepared scenarios related to the use of cloud service features that use being misused. Data acquisition techniques use the method of direct acquisition and physical imaging to obtain digital evidence. The experimental results showed that after scenario 1 and scenario 3, information on the file name and directory of the paths downloaded by client 1 and client 2 were obtained with information on the IP address, mac address, user name, password and time stamp. After scenario 2, digital evidence has been obtained that contains information on the name and location of the folder on the cloud server. After scenario 4, information on the name of the file and the shared folder is successfully obtained, equipped with client information that has the right to access the files and folders. After scenario 5, information about the file name and directory of the file path is successfully obtained.
\end{abstract}

Keywords: Data Acquisition, Digital Evidence, Cloud Computing, NIST 800-86.

\section{PENDAHULUAN}

Layanan cloud computing merupakan kolaborasi pemanfaatan teknologi komputasi dan pengembangan sistem berbasis internet yang menawarkan fasilitas sumber daya tanpa perangkat tambahan, biaya yang lebih terjangkau dan penyimpanan data yang tidak terbatas. Secara umum terdapat tiga jenis layanan pada cloud computing yaitu: Cloud Software as a service (SaaS), Cloud Platform as a Service (PaaS) dan Cloud Infrastructure a Service (IaaS). Sedangkan cloud computing menurut NIST berdasarkan sifat jangakauannya terdapat empat model, yaitu: Private Cloud, Public Cloud, Community Cloud dan Hybrid Cloud [1]. Organisasi maupun perusahaan sudah banyak yang menggunakan layanan ini untuk mendukung kelancaran proses bisnis dan efisiensi penyimpanan arsip digital [2]. Private cloud mencakup seluruh cloud infrastructure termasuk sumber daya hardware yang dimiliki organisasi maupun perusahaan tersebut [2]. Namun, selain memiliki banyak manfaat cloud juga membawa dampak negatif diantaranya penyalahgunaan cloud untuk menyimpan data hasil kejahatan.

Merujuk masalah tersebut, maka diperlukan metode untuk menangani kasus kejahatan cyber, yaitu dengan menggunakan teknik akuisisi data untuk menganalisa dan mengumpulkan bukti-bukti digital dari tindak kejahatan. Penanganan kejahatan cyber tersebut diperlukan teknik akuisisi data, dimana teknik akusisi data dapat dilakukan secara live system ataupun write-block system [3]. Kedua teknik akuisisi data tersebut tidak hanya dilakukan pada layanan cloud computing, melainkan dapat dilakukan juga pada computer client, server, laptop atau notebook dan smartphone [3]. 
Berbagai analisis forensik digital untuk menemukan bukti dari suatu aktivitas kriminal berbasis layanan cloud computing pernah dilakukan dalam penelitian sebelumnya, diantaranya: menggunakan metode The Advance Data Acquisition Model (ADAM) [4], metode End to End Digital Investigation (EEDI) [5], National Institute of Standard and Technology (NIST) [6], National Institute of Justice ( NIJ ) [7]. Penelitian [4] berhasil menemukan lokasi files folder data digital evidences, username dan password, timestamps, ip address dan macaddress, dan kesesuaian file-file data digital evidence yang didapatkan pada perangkat smartphone, komputer desktop dan pada komputer private cloud computing. Penelitian [5] berhasil mendapatkan aktivitas yang tersimpan pada cache browser, username password, logs chatting mIRC, e-mail, file dalam MS Word. Penelitian [6] berhasil mengungkap bukti kejahatan dari lalu lintas jaringan pada layanan ownCloud. Penelitian [7] berhasil menerjemahkan kode-kode hexsa hasil akuisisi untuk menghasilkan barang bukti yang yang bisa di mengerti oleh hakim.

Penelitian ini bertujuan untuk melakukan akuisisi data bukti digital menggunakan metode NIST melalui simulasi dari beberapa skenario yang mencakup fitur cloud yang sering digunakan, serta skenario yang dapat menghilangkan bukti digital. Bukti digital dan perubahan yang disebabkan oleh aktivitas yang dilakukan pada skenario tersebut dianalisis dan ditampilkan ke dalam bentuk tabel. Proses analisa dilakukan untuk menyimpulkan karakteristik bukti digital dari layanan cloud computing yang diteliti.

\section{METODE PENELITIAN}

\subsection{Proses Akuisisi Data}

Proses akuisisi data untuk mendapatkan informasi dari bukti digital mengikuti tahapan dari metode National Institute of Standards Technology (NIST) [8].

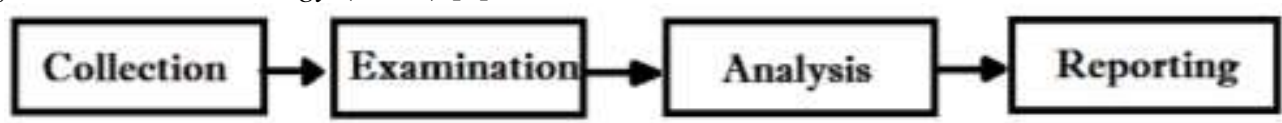

Gambar 1. Tahapan Metode NIST 800-86

Berdasarkan gambar 1 hal ini dapat dijelaskan tahap akuisisi data sebagai berikut:

a. Collection: proses akuisisi data dilakukan dengan teknik live acquisition dan imaging pada database server layanan ownCloud.

b. Examination: proses pemeriksaan terhadap data barang bukti menggunakan tool HashCalc dan diberi Hash Message Digest 5 (MD5) untuk menjaga integritas data.

c. Analysis: Data bukti digital yang ditemukan pada tahap examination dianalisis untuk membuat kesimpulan dari bukti digital. File hasil live acquisition dan database ownCloud yang relevan akan dibuka dan dianalisis menggunakan tools Wireshark, Network Miner dan Magic ISO Maker.

d. Reporting: Investigator melaporkan hasil investigasi beserta bukti digital yang ditemukan. Pelaporan dalam penelitian meliputi penyajian artefak digital yang telah disimpulkan dari tahap analisis.

\subsection{Hardware dan Software Yang Digunakan}

Perangkat keras dan perangkat lunak yang digunakan dalam penelitian ini ditampilkan pada Tabel 1 dan Tabel 2.

Tabel 1. Hardware Yang Digunakan

\begin{tabular}{clcl}
\hline No & Hardware & Spesifikasi & \multicolumn{1}{c}{ Keterangan } \\
\hline 1 & PC Server & Asus A455L, Windows 10 64-bit & Komputer server \\
2 & PC Client & Toshiba Tecra Z40t, Windows 10 64-bit & Komputer Client 1 \\
3 & Smartphone & Samsung Galaxy S5 G900H & Smartphone Client 2 \\
\hline
\end{tabular}

Tabel 2. Software Yang Digunakan

\begin{tabular}{cll}
\hline No & \multicolumn{1}{c}{ Software } & \\
\hline 1 & OwnCloud & Layanan Cloud yang akan dianalisa. \\
2 & Apache Server & Server local ownCloud. \\
3 & MySQL & Database server ownCloud. \\
4 & Wireshark & Tool live acquisition lalu lintas data pada layanan ownCloud. \\
5 & Network miner & Tool untuk menganalisia file hasil live acquisistion. \\
6 & Magic ISO Maker & Tool imaging bukti digital server ownCloud. \\
7 & HashCalc & Tool untuk memeriksan nilai hash file bukti digital. \\
8 & Chrome Browser & Browser yang digunakan server.
\end{tabular}




\subsection{Perancangan Skenario Kasus}

Skenario dibuat untuk merekontruksi aksi relevan yang mungkin pengguna lakukan dalam tindakan kejahatan cyber dan menyembunyikan jejaknya[2]. Pembuatan skenario dilakukan berdasarkan hasil analisa fungsionalitas layanan cloud. Skenario mencakup fitur-fitur layanan cloud yang berpotensi disalahgunakan untuk tindakan kejahatan, serta skenario yang dapat menghilangkan bukti digital.

a. Skenario 1 : Client Mengunduh File dari Server.

b. Skenario 2 : Client Membuat Folder Baru.

c. Skenario 3 : Client Mengunggah File.

d. Skenario 4 : Client Membagikan Folder/File Ke Sesama Pengguna Cloud.

e. Skenario 5 : Client Menghapus File

Skenario simulasi yang telah dibuat selanjutnya akan diterapkan pada layanan ownCloud yang telah disiapkan. Saat setiap skenario dijalankan, akan diteliti fitur-fitur pada aplikasi yang terkait dengan skenario, sehingga diketahui bukti digital yang masih ditinggalkan dari penggunaan fitur tersebut serta karakteristiknya. Beberapa dari skenario merupakan aktivitas yang dapat merubah dan menghilangkan bukti digital.

\section{ANALISA DAN PEMBAHASAN}

\subsection{Collection}

OwnCloud menyimpan berbagai data yang digunakan ketika dijalankan. Data-data tersebut tersimpan dalam folder khusus seperti terlihat pada tabel 3.

Tabel 3. Lokasi Bukti Digital Layanan OwnCloud

\begin{tabular}{ll}
\hline \multicolumn{1}{c}{ Bukti Digital } & \multicolumn{1}{c}{ Lokasi } \\
\hline Database ownCloud & lowncloud\data \\
\hline Database Server & Imysqlldatalowncloud \\
\hline Unggah File & lowncloud\dataluser*|files \\
\hline Hapus File & lowncloud\dataluser*|files-trashbin\files \\
\hline Data Folder & lowncloud\dataluser*|files \\
\hline
\end{tabular}

Keterangan : user* = nama folder sesuai dengan nama pengguna

\subsection{Examination}

Proses examination merupakan aktivitas pemeriksaan barang bukti hasil akuisisi data sebelum barang bukti diperiksa oleh investigator. Akuisisi barang bukti dilakukan dengan melakukan pemeriksaan nilai hash pada file tersebut. Pemeriksaan nilai hash MD5 dilakukan dengan menggunakan tool HashCalc.Hasil pemeriksaan nilai Hash disajikan pada tabel 4.

Tabel 4. Nilai Hash MD5 Barang Bukti

\begin{tabular}{lc}
\hline \multicolumn{1}{c}{ Nama File } & MD5 \\
\hline akuisisi_dari_server_cloud.iso & e6b674731f63ea75f8ac5b 7444ae2308 \\
analisis_owncloud_PC_Client_I_v2.pcap & 50be296230d006217604bf5dca9987c8 \\
analisis_owncloud_android_II.pcap & f4afe2ecb6d2cdaa82a79e29f76a7ad8 \\
digital_evidence_browser_client1.iso & 783169194ec60c2b1ee5c2f3f7 abd16e \\
browser_artefact_client2.zip & 3fcf3dc8607d357b00cee3536df9f9ff \\
\hline
\end{tabular}

\subsection{Analysis}

Pada tahap awal, proses analisis dilakukan pada file *.pcap hasil live acquisistion client 1 dan client 2 serta file imaging database ownCloud.

a. Analisa File "analisis_owncloud_PC_Client_I_v2.pcap"

\begin{tabular}{|l|l|}
\cline { 2 - 3 } & $>$ Frame 1376: 748 bytes on wire (5984 bits), 748 bytes captured (5984 bits) \\
& $>$ Ethernet II, Src: IntelCor_43:e6:da (5c:c5:d4:43:e6:da), Dst: Azurewav_31:ee:e5 (f0:03:8c:31:ee:e5) \\
& $>$ Internet Protocol Version 4, Src: 172.20.10.14, Dst: 172.20.10.3 \\
& $>$ Hypertext Transfer Protocol \\
& $>$ HTML Form URL Encoded: application/x-www-form-urlencoded \\
& $>$ Form item: "user" = "user1@owncloud.com \\
& $>$ Form item: "password" = "admin1" \\
& $>$ Form item: "timezone-offset" = "7" \\
& $>$ Form item: "requesttoken" = "fc1d6490067a84a063a3"
\end{tabular}


Gambar 2 menunjukan client 1 melakukan login ke layanan ownCloud dengan menggunakan username "user1@owncloud.com" dan password "admin1". Client 1 mengakses layanan owncloud melalui host dengan ip address 172.20.10.14 dan mac addrees "5c:c5:d4:43:e6:da" dengan port 60064.

b. Analisis File "analisis_owncloud_android_II.pcap"

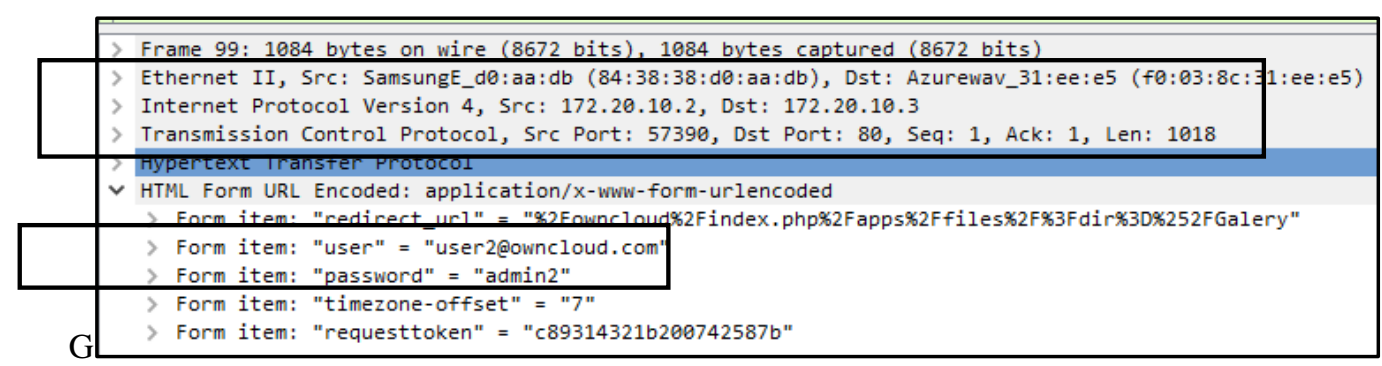

Gambar 3. User Credential Client 2

Gambar 3 menunjukan informasi Client 2 melalui IP address 172.20.10.2 mengakses layanan ownCloud menggunakan username "user2@owncloud.com" dan password "admin2". Client 2 menggunakan mac addrees "84:38:38:d0:aa:db" dengan port 57390.

c. Analisa Device yang mengakses layanan OwnCloud

Analisa yang dilakukan juga berhasil mendapatkan informasi nama sistem operasi yang digunakan oleh setiap device yang mengakses layanan owncloud. Informasi nama sistem operasi beserta parameter lainnya yang berhasil diperoleh seletah dilakukan analisa ditampilkan pada Tabel 5.

Tabel 5. Data Device Yang Mengakses Layanan ownCloud

\begin{tabular}{lccc}
\hline \multicolumn{1}{c}{ Data } & Server & Client 1 & Client 2 \\
\hline Sistem Operasi & Windows & Windows & Android \\
IP Address & 172.20.10.3 & 172.20.10.14 & 172.20.10.2 \\
Mac Address & F0:03:8C:31:EE:E5 & 5C:C5:D4:43:E6:DA & 84:38:38:D0:AA:DB \\
Paket Dikirim & 15391 paket & 5762 paket & 6824 paket \\
Paket Diterima & 12397 paket & 10345 paket & 4463 paket \\
\hline
\end{tabular}

d. Analisa Database OwnCloud

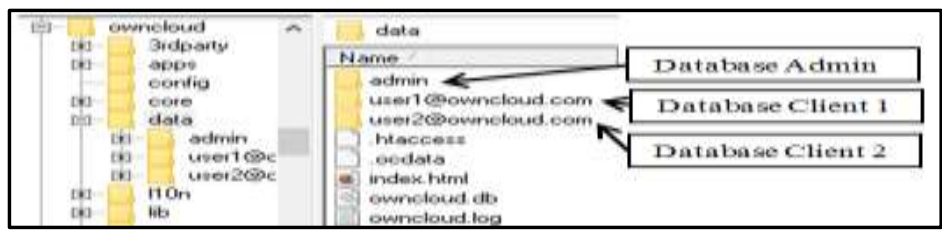

Gambar 4. Struktur Direktori database OwnCloud

Lokasi database ownCloud dapat ditemukan pada direktori "lowncloudldata" seperti ditampilkan pada gambar 4. Direktori tersebut menyimpan database pengguna ownCloud. Berkas media yang diunggah ke ownCloud seperti: dokumen, gambar, dan video disimpan pada direktori "lowncloudldataluserlfiles". File yang dihapus berada pada direktori”’owncoudldataluser|files-trashbin\files".

\subsection{Reporting}

Berikut laporan bukti digital yang berhasil disusun berdasarkan skenario yang telah dirancang sebelumnya dalam penggunaan fungsional layanan owncloud.

a. Skenario 1 : Client Mengunduh File dari Server.

\begin{tabular}{|c|c|c|c|c|}
\hline \multicolumn{5}{|c|}{ 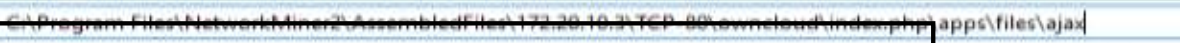 } \\
\hline \multirow{9}{*}{$\begin{array}{l}4 \\
4\end{array}$} & Name & Date modified & Type & $\sin { }^{*}$ \\
\hline & [DAB V HASIL DAN PEMBAHASAN,doCK & $14 / 05 / 201916.18$ & Docx File & $5.968 \mathrm{~KB}$ \\
\hline & magang (5).JPG & $14 / 05 / 201916.18$ & JPG File & $2.114 \mathrm{~KB}$ \\
\hline & magang $(10) . J P G$ & $11 / 05 / 201016,36$ & JPG File & $1, \mathrm{nog} \mathrm{KB}$ \\
\hline & magang (9).JPG & $11 / 05 / 201916.36$ & JPG File & $1.562 \mathrm{~KB}$ \\
\hline & BAB IV PROFIL LOKASI MAGANG.dOCK & $14 / 05 / 201916.18$ & Docxfile & $385 \mathrm{~KB}$ \\
\hline & ANALISIS KASUS, docX & $11 / 05 / 201916.36$ & Docx file & $100 \mathrm{~KB}$ \\
\hline & $\nabla$ magang (2).JPG & $14 / 05 / 201916.18$ & JPOFile & $53 \mathrm{~KB}$ \\
\hline & DAFTAR PELAKU P,doeK & $14 / 05 / 201916.21$ & Docxfite & $13 \mathrm{~KB}$ \\
\hline
\end{tabular}

Gambar 5. Bukti Digital File yang diunduh

Irfan Helmi | http://ejurnal.stmik-budidarma.ac.id/index.php/mib | Page 220 
Aktivitas mengunduh file dari layanan ownCloud berhasil ditemukan file path-nya secara utuh menggunakan teknik live acquisiton pada direktori "C:IProgram Files\NetworkMiner2 \AssembledFiles $\backslash 172.20 .10 .3 \backslash T C P$ 80 \owncloudlindex.phplapps\fileslajax" seperti ditampilkan pada gambar 5. File yang diunduh client 1 yaitu "BAB V HASIL DAN PEMBAHSAN.docx, magang (5).JPG, BAB IV PROFIL LOKASI MAGANG, magang (2).JPG dan DAFTAR PELAKU P.docx". Client 2 mengunduh file magang (10).JPG, magang (9).JPG dan ANALISIS KASUS.docx. Teknik imaging pada database ownCloud tidak menemukan log dari skanario tersebut.

b. Skenario 2 : Client Membuat Folder Baru.

1. Client 1 Membuat Folder Baru

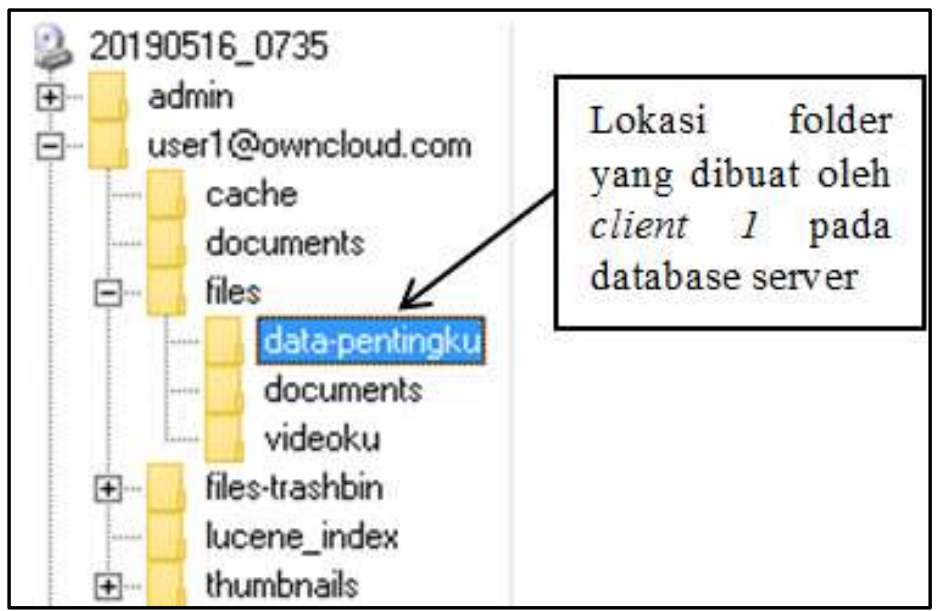

Gambar 6. Folder Client 1

Aktivitas client 1 membuat folder baru tersimpan pada direktori "lowncloudldataluser1 @owncloud.com\files" pada database ownCloud seperti terlihat pada gambar 6. Folder yang dibuat oleh cient 1 pada layanan ownCloud yaitu folder "data pentingku, documents dan videoku".

2. Client 2 Membuat Folder Baru

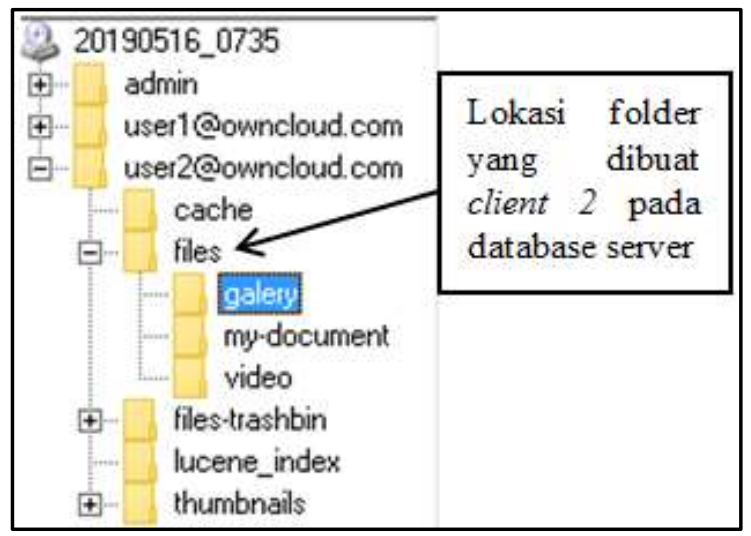

Gambar 7 Folder Client 2

Aktivitas client 2 membuat folder baru tersimpan pada direktori "lowncloudldataluser2 @owncloud.comlfiles" pada database ownCloud seperti terlihat pada gambar 7. Folder yang dibuat oleh cient 2 pada layanan ownCloud yaitu folder "galery, my-document dan video".

c. Skenario 3 : Client Mengunggah File.

1. Bukti Digital Client 1 Mengunggah File

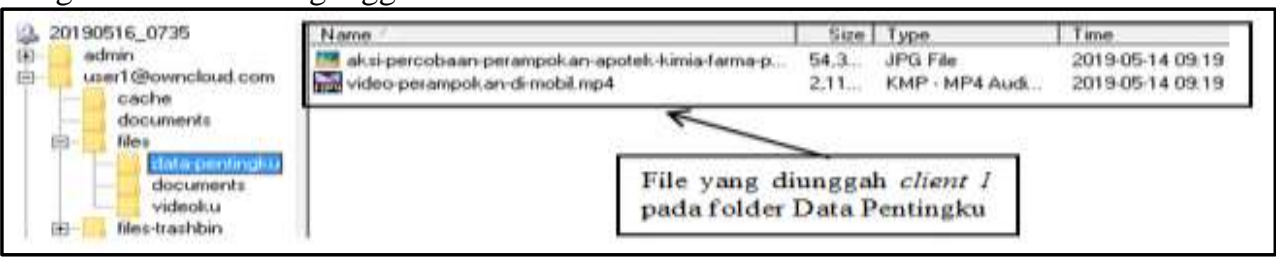

Gambar 8. Bukti Digital File Yang Diunggah Client 1 
Bukti digital dari Skenario 3 berhasil diakuisisi pada direktori "lowncloudldataluser1 @owncloud.comlfiles\data-pentingku" seperti terlihat pada gambar 8. File yang diunggah client 1 adalah "aksi-percobaan-perampokan-apotek-kimia-farma-pelaku-pakai-pistol-mainan.jpg dan videoperampokan-di-mobil.mp4" sedangkan file dokumen yang diunggah kemudian dihapus tidak ditemukan pada database ownCloud. Bukti digital file yang dihapus oleh client 1 berhasil diakuisisi dengan teknik live acquisition (gambar 9).

\begin{tabular}{|c|c|c|c|c|c|}
\hline \multicolumn{6}{|c|}{ C:\Program Files \NetworkMiner2\AssembledFiles $\backslash 172.20 .10 .14 \backslash T C P-60593 \backslash D A F T A R$ PELAKU PENGEDAR NARKOBA.docx } \\
\hline$\wedge$ & Name & Date modified & Type & Size & \\
\hline & D DAFTAR PELAKU P.docX & $14 / 05 / 201916.23$ & DOCX File & & $13 \mathrm{~KB}$ \\
\hline
\end{tabular}

Gambar 9. Bukti Digital File Yang Diunggah Kemudian Dihapus

Barang bukti file yang dihapus oleh client 1 berhasil diakuisisi menggunakan teknik live acquisistion pada direktori "C:Program Files\NetworkMiner2\AssembledFiles \172.20.10.14\TCP-60593।" dengan nama file "DAFTAR PELAKU PENGEDAR NARKOBA.docx.

\section{Bukti Digital Client 2 Mengunggah File}

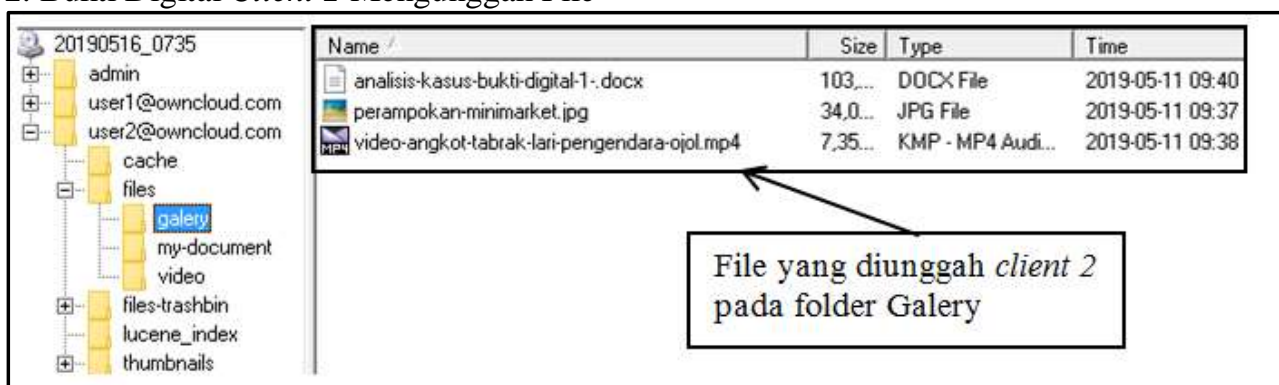

Gambar 10. Bukti Digital File Yang Diunggah Client 2

Bukti digital aktivitas client 2 menggunggah file berhasil diakuisisi pada direktori "lowncloud\dataluser2@owncloud.com\files\galery", file yang diunggah client 2 adalah "analisis-kasusbukti-digital-1.docx, perampokan minimarket.jpg dan video-angkot-tabrak-lari-pengendara-ojol.mp4".

d. Skenario 4 : Client Men-share Folder/File Ke Sesama Pengguna Cloud.

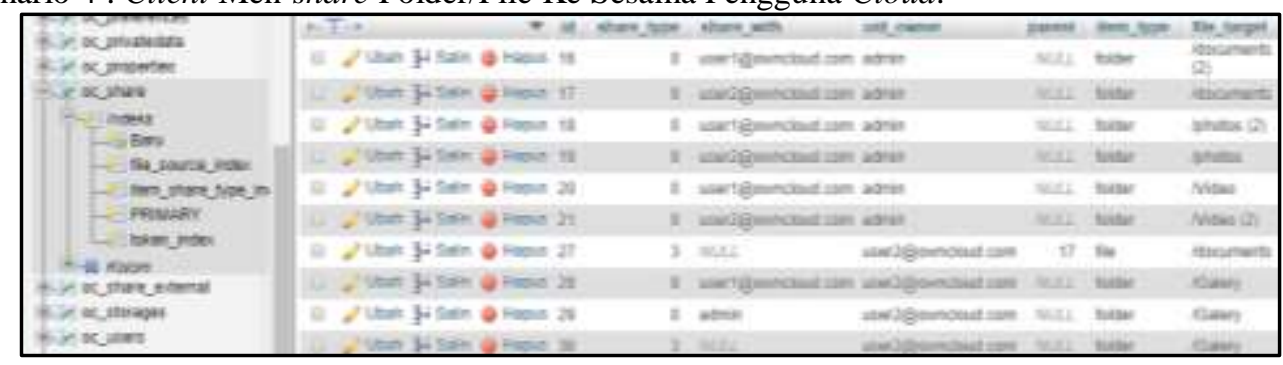

Gambar 11. Bukti Digital Share Folder/File

Skenario 4 yaitu client men-share file/folder ke pengguna lain. Bukti digital dari Client 2 yang men-share folder "Galery" berhasil diakuisisi pada database server ownCloud "oc_share" pada phpmyadmin, sedangkan data client 1 yang men-share file dokumen lalu menghapus file dokumen yang telah dibagikan ke client 2 tidak ada di database server.

e. Skenario 5 : Client Menghapus File

Skenario 5 hanya dilakukan oleh client 1 sebagai pengguna PC karena client 2 yang mengakses layanan ownCloud menggunakan smartphone tidak memiliki fitur menghapus file maupun folder pada layanan ownCloud.

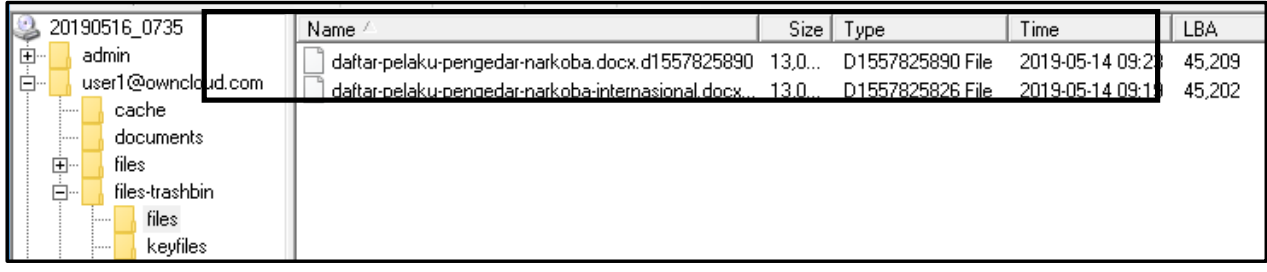

Gambar 12. Bukti Digital Client 1 Menghapus File

Irfan Helmi | http://ejurnal.stmik-budidarma.ac.id/index.php/mib | Page 222 
Aktivitas client 1 menghapus file berhasil diakuisisi pada direktori "owncloudldataluser1 @owncloud.comlfiles-trashbinlfiles", file yang dihapus tersebut adalah "daftar-pelaku-pengedarnarkoba.docx dan daftar-pelaku-pengedar-narkoba-internasional.docx".

\section{IMPLEMENTASI}

\subsection{Hasil Akuisisi Data Secara Live Acquisition dan Imaging}

Hasil analisis akuisisi data secara live acquisiton dan imaging bukti digital dari simulasi fungsional layanan ownCloud pada penelitian ini disusun dalam tabel bukti digital yang ditemukan seperti pada Tabel 6 dan Tabel 7 .

Tabel 6. Data Bukti Digital Yang Berhasil Ditemukan

\begin{tabular}{clcc}
\hline No & \multicolumn{1}{c}{ Skenario } & Client 1 & Client 2 \\
\hline 1 & Unduh File & $\sqrt{ }$ & $\sqrt{ }$ \\
2 & Membuat Folder Baru & $\sqrt{ }$ & $\sqrt{ }$ \\
3 & Unggah File & $\sqrt{ }$ & $\sqrt{ }$ \\
4 & Share File / Folder & $\sqrt{ }$ & $\sqrt{ }$ \\
5 & Menghapus File & $\sqrt{ }$ & - \\
\hline Keterangan : & &
\end{tabular}

$\sqrt{ }:$ Ditemukan, $\times$ : Tidak ditemukan, - : Skenario tidak dilakukan

Tabel 7. Parameter Pendukung Bukti Digital

\begin{tabular}{clcc}
\hline No & \multicolumn{1}{c}{ Parameter } & Client 1 & Client 2 \\
\hline 1 & IP Source & $\sqrt{ }$ & $\sqrt{ }$ \\
2 & Mac Address Source & $\sqrt{ }$ & $\sqrt{ }$ \\
3 & IP Destination & $\sqrt{ }$ & $\sqrt{ }$ \\
4 & Mac Address Destination & $\sqrt{ }$ & $\sqrt{ }$ \\
5 & Struktur Folder dan File & $\sqrt{ }$ & $\sqrt{ }$ \\
6 & Log Activity & $\sqrt{ }$ & $\sqrt{ }$ \\
7 & Username and Password & $\sqrt{ }$ & $\sqrt{ }$ \\
8 & Time Stamp & $\sqrt{ }$ & $\sqrt{ }$ \\
9 & Data Locations & $\sqrt{ }$ & $\sqrt{ }$ \\
10 & Protocol and Port Access & $\sqrt{ }$ & $\sqrt{ }$ \\
\hline
\end{tabular}

\section{KESIMPULAN}

Berdasarkan peneletian ini, maka dapat disimpulkan bahwa bukti digital hasil akuisisi data secara live acquisition dan imaging berdasarkan skenario yang dilakukan adalah sebagai berikut. Bukti digital skenario 1 dan skenario 3 berhasil mendapatkan detail nama file dan direktori path file yang diunduh oleh client 1 dan client 2 dilengkapi dengan data ip address, mac address, username dan password, timestamp dan data lainnya yang mendukung bukti digital skenario tersebut. Skenario 2 berhasil mendapatkan bukti digital berupa nama dan lokasi folder di cloud. Skenario 4 berhasil mendapatkan nama file dan folder yang di-share dilengkapi dengan data client yang mendapatkan hak akses file dan folder tersebut. Hasil skenario 5 berhasil mendapatkan detail nama file dan direktori path file yang dihapus oleh client 1. Client 2 tidak melakukan skenario 5 karena layanan ownCloud pada smartphone tidak memiliki fitur hapus file maupun folder.

\section{REFERENCES}

[1] NIST (National Institute of Standards and Technology), "The attached DRAFT document ( provided here for HISTORICAL purposes ) has been superseded by the following publication", 2012.

[2] M. S. Asyaky, “Analisis dan Perbandingan Bukti Digital Aplikasi Instant Messenger Pada Android,” vol. 3, pp. 220-231, 2019.

[3] M. Lessing and Van, S. B., "Live forensic acquisition as alternative to traditional forensic processes", 2016.

[4] N. Widiyasono, I. Riadi, and A. Luthfi, "Investigasi, Penerapan Metode ADAM Pada Proses Computing, Layanan Private Cloud," 2016.

[5] I. Febrian, E. Kurdiat, N. Widiyasono, and H. Mubarok, "Analisis Proses Investigasi Dekstop PC Yang Terhubung Layanan Private Cloud," vol. 2, pp. 221-230, 2016.

[6] P. Yakub, "Network Forensic Pada Jaringan Berbasis Awan," Mei 2017.

[7] A. Yudhana, R. Umar, and A. Ahmadi, "Akuisisi Data Forensik Google Drive Pada Android Dengan Metode National Institute of Justice ( NIJ )," vol. X, no. X, pp. 8-13.

[8] R. Umar, I. Riadi, and G. M. Zamroni, “Mobile Forensic Tools Evaluation for Digital Crime Investigation,” vol. 8, no. 3, pp. 949-955, 2018.

[9] A. Aziz, Muhammad, "Analisis Forensik Line Messenger Berbasis Web Menggunakan Framework National Institute Of Justice (NIJ)," in Seminar Nasional Informatika. Yogyakarta, 2018. 
[10] Furht, Borko and Armando Escalante, “Handbook of Cloud Computing,” New York : Springer, 2010.

[11] Hendri, "Analisis Resiko Implementasi Teknologi Cloud Computing Pada Infrastruktur Saas (Software As A Service)," vol. 8, pp. 3240, 2013

[12] H. Lovell, W. Maxwell and C. Wolf, "DCA Global Reality: Governmental Access to Data in the Cloud A comparative analysis of ten international jurisdictions," Hogan Lovell White papers.13, 2012.

[13] Howard, John D, "An Analysis Of Security Incidents On The Internet 1989 - 1995," PhD thesis, Engineering and Public Policy, Carnegie Mellon University. 1997

[14] I. Riadi and I. Anshori, “Analisis Bukti Digital Facebook Messenger Menggunakan Metode NIST,” vol. 3, pp. 13-21, 2018.

[15] R. Imam, "Analisis Forensik Bukti Digital Pada Frozen Solid State Drive Dengan Metode National Institute Of Standards And Technology (NIST) “,Vol. 2, pp. 33-40, 2017.

[16] R. Tri, "Live Forensik Untuk Analisa Anti Forensik Pada Web Browser Studi Kasus Browzar,” vol. 1, pp. 32-38, 2018.

[17] Wardhana, Indrawata. "Membangun Owncloud Cloud Storage," IAIN, 2016.

[18] Yudhana, Anton. 2018. “Analisis Bukti Digital Facebook Messenger Menggunakan Metode NIST,” Vol. 3, pp. 13-21, 2018. 